\title{
Acute bilateral emphysematous pyelonephritis
}

\author{
John Surur \\ Department of Acute Medicine/Anaesthetics, Kings College Hospital, Westminster, London, UK \\ Correspondence to Dr John Surur, jsurur_surur@yahoo.com
}

\begin{abstract}
Summary
The author reports the case of a well and fit patient who presented herself to the emergency department and was found to have bilateral emphysematous pyelonephritis. She was admitted to the intensive care where she was initially treated conservatively with antibiotics, percutaneous drainage and continuous renal replacement therapy, but her condition deteriorated. She underwent a left total nephrectomy and a partial right nephrectomy that resulted in remarkable improvement. The patient started passing urine spontaneously, so no haemofiltration was required. She was discharged home and her case was followed-up by an urologist and nephrologist. This case lays emphasis on thoroughly investigating and managing a patient with bilateral emphysematous pyelonephritis and, in relation to its management, on the dilemma of whether the treatment of choice should be conservative or surgical.
\end{abstract}

\section{BACKGROUND}

Emphysematous pyelonephritis is a rare necrotising pyelonephritis with a variable clinical picture ranging from mild abdominal pain to septic shock. It is a life-threatening condition that usually affects patients with diabetes, and a small percentage may be due to urinary tract obstruction. ${ }^{12}$ Traditionally, surgery was considered mandatory and the treatment of choice. In bilateral cases of the disease, surgically treated patients required long-term dialysis. If left untreated the outcome was usually fatal. In our patient, the predisposing factor could be due both to obstruction due to renal papillary cell carcinoma and to undiagnosed diabetes resulting in gas formation, which caused impaired tissue perfusion leading to the emphysematous pyelonephritis. I decided to write about this case because it was rare and presented a treatment dilemma. Aside from my knowledge gained from looking through the literature, I had heard of no one who had undergone total and partial nephrectomies and been discharged home with a kidney functioning at two-thirds capacity. It was also a complex case, with two predisposing factors in the form of diabetes mellitus and obstructive uropathy due to renal papillary carcinoma.

\section{CASE PRESENTATION}

A 64-year-old woman presented to the emergency department after she was found at home by her niece, collapsed. Apart from a history of mild asthma, she was generally fit and well. On admission she was found to have a low Glasgow Coma Scale (GCS) 11/15, and to be hypotensive with blood pressure (BP) at 70/35 $\mathrm{mm} \mathrm{Hg}$ and tachycardic with a heart rate of $125 \mathrm{bpm}$. The findings from cardiovascular and respiratory examination were unremarkable. Her abdomen was soft but tender at her renal angles, bilaterally. She was resuscitated with intravenous fluids and intravenous antibiotics (4.5 g piperacillin/tazobactam and $350 \mathrm{mg}$ of $5 \mathrm{mg} / \mathrm{kg}$ gentamicin), and her blood was sent for routine blood tests and blood culture. She was catheterised and the urine looked purulent. A urine dipstick showed leucocytes, nitrates and glucose, but no ketones.
Blood glucose (BM) was $50 \mathrm{mmol} / \mathrm{l}$. She was not known to be diabetic. She was started on an insulin sliding scale for possible hyperosmolar non-ketotic diabetic coma. Despite all the resuscitation efforts, she failed to respond and subsequently deteriorated; her GCS dropped to 8/15. She was intubated and admitted to our intensive care unit for organ support. On admission to intensive care unit, she was in septic shock and was oliguric, required administration of inotropes and renal replacement therapy.

\section{INVESTIGATIONS}

Important blood tests made on her admission showed random blood glucose at $55.8 \mathrm{mmol} / \mathrm{l}$, urea at $58.9 \mathrm{mmol} / \mathrm{l}$, creatinine at $418 \mathrm{mmol} / \mathrm{l}$, sodium at $145 \mathrm{mmol} / \mathrm{l}$, potassium at $4.7 \mathrm{mmol} / \mathrm{l}$, total white cell count at $23.90 \times 1010 / 1$ and $C$ reactive protein at $458.2 \mathrm{mg} / \mathrm{l}$. A CT scan showed extensive gas bilaterally in the renal parenchyma, with perinepheric oedema. Blood, urine and drainage fluid cultures all showed Klebsiella pneumoniae sensitive to coamoxiclav, piperacillin/tazobactam and gentamicin. The susceptibility of the organism to the co-amoxiclav was 1 $\mathrm{mg} / \mathrm{l}$ - a minimal inhibitory concentration (MIC), the gentamicin MIC was $2 \mathrm{mg} / \mathrm{l}$ and the piperacillin/tazobactam MIC was $1 \mathrm{mg} / \mathrm{l}$ (figure 1).

\section{DIFFERENTIAL DIAGNOSIS}

- Retroperitoneal perforation of an abdominal viscus

- Psoas abscess secondary to gas-forming organisms

- Reflux of air from the bladder

- Bronchorenal, enterorenal or cutaneorenal fistulae (as may occur with xanthogranulomatous pyelonephritis)

- Air in a focal renal abscess (not life threatening).

\section{TREATMENT}

She was mechanically ventilated, sedated with propofol and fentanyl and started on inotrope (norepinephrine) to support her BP and to promote urine production. She was then put on renal replacement therapy (filtration) to help and support her kidneys, and she was started on an insulin 


\section{BMJ Case Reports}

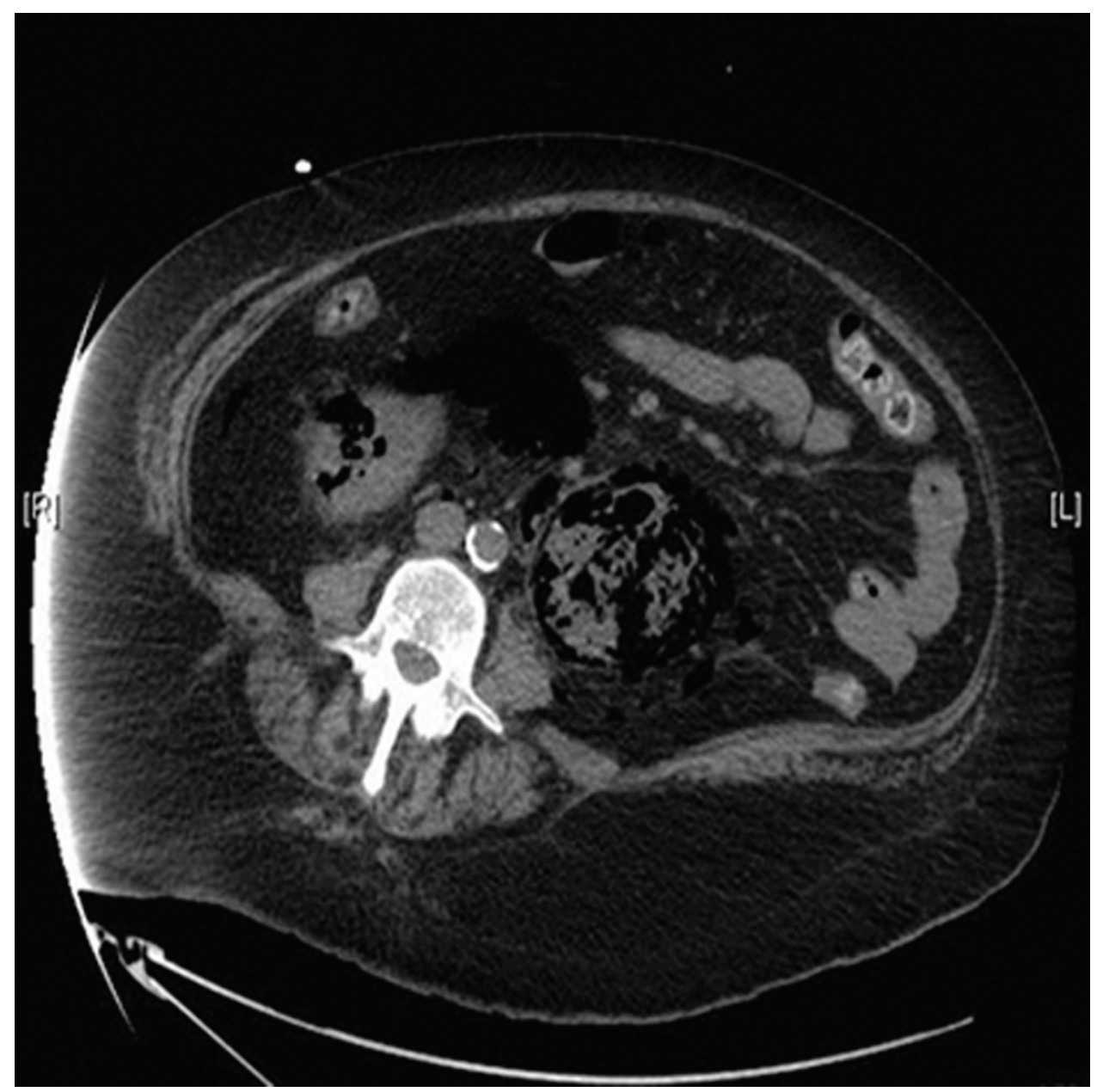

Figure 1 CT scan of the abdomen.

sliding scale. She was initially treated conservatively with percutaneous renal drainage plus antibiotics. Despite this, her condition remained static, and required high inotropic support and continuous renal filtration. Sedation was switched off 1 day after admission to the intensive treatment unit (ITU), but her GCS remained low, at 3/15, $48 \mathrm{~h}$ after sedation was stopped.

Despite being treated with $4.5 \mathrm{~g}$ piperacillin/tazobactam three times a day and $350 \mathrm{mg}$ of gentamicin once daily, there was no improvement in her condition. Her gentamicin levels were taken at 09:00 and her doses given at 22:00, daily. The level was less than $1 \mathrm{mg} / \mathrm{l}$ each time, within the therapeutic range. Her antibiotic doses were not reduced despite renal impairment, because she was on haemofiltration. Following the microbiologist's advice, piperacillin/tazobactam was changed to $1.2 \mathrm{mg} / \mathrm{l}$ co-amoxiclav three times daily beginning on the fourth day after admission, but still there was no improvement in her condition. The reasoning behind changing from piperacillin/ tazobactam to co-amoxiclav was that the susceptibility was similar for both co-amoxiclav and piperacillin/tazobactam, and the cost effectiveness of co-amoxiclav was preferable, because only one species of organism had been grown from all three different samples sent for culture. In addition it would reduce the chance of the emergence of strains resistant to the piperacillin/tazobactam. She had a repeat abdominal CT scan that showed no changes from the initial scan, despite her treatment with percutaneous drainage plus antibiotics; thus, it was decided that she needed an operation (figure 2).

She underwent a left kidney nephrectomy and a onethird resection of the right kidney on fifth day, postadmission. One day postoperatively she began passing urine, and she was weaned off sedation and inotropes. Within a few hours she woke up and was extubated. She made a remarkable recovery and was discharged from the ITU to the ward under the care of the urology and diabetic team for her newly diagnosed diabetes. Her histology showed left kidney papillary renal cell carcinoma with areas of acute inflammation, along with necrosis. The tumour's size was estimated to be $4 \mathrm{~cm}$ in its maximum dimension. It had infiltrated the renal calyces but did not breach the renal capsule. The renal vein was free of the tumours. The ureteric resection margin was also tumour-free. Her right kidney showed fat and necrosis.

\section{OUTCOME AND FOLLOW-UP}

She was discharged home, with a 3-6 months CT scan follow-up. She also received oral hypoglycaemic treatment for diabetes. She was reviewed in September 2010 at the urology clinic and was found to be doing well. She still did not need dialysis. 


\section{BMJ Case Reports}

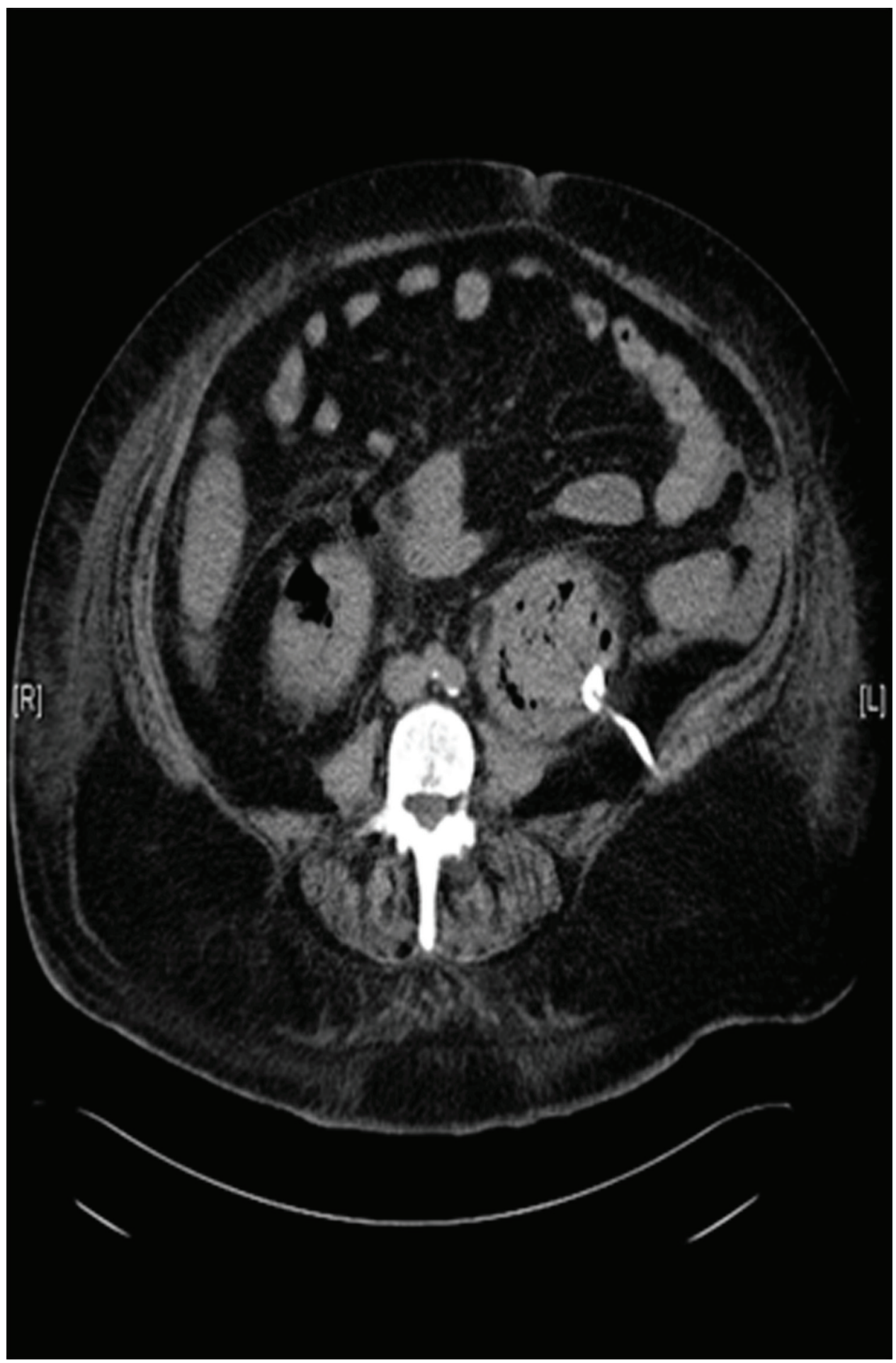

Figure 2 CT guided percutaneous drainage of emphysematous pyelonephritis.

\section{DISCUSSION}

Emphysematous pyelonephritis was described in 1898 by Kelly and MacCallum. ${ }^{3}{ }^{4}$ It is an acute necrotising parenchymal and perirenal infection caused by gas-forming uropathogens, ${ }^{35} 6$ and currently there have been 200 cases reported worldwide. Predisposing factors include gas-forming bacteria, high tissue glucose, defective immune response and impaired tissue perfusion. ${ }^{7}$ Diabetic patients account for more than $70 \%$ of cases, and patients with urinary obstruction account for $20 \% .{ }^{6}$ The organisms commonly responsible for causing emphysematous pyelonephritis are Escherichia coli, Klebsiella pneumoniae, Proteus mirabilis, Pseudomonas aeruginosa, Citrobacter and, rarely, yeast. ${ }^{10}$ If left untreated the condition is uniformly fatal.

The mortality from using current therapy ranges from $10 \%$ to $40 \%$, with patients treated medically having higher mortality than those treated surgically $(70 \%$ vs $30 \%$, respectively. 56811 Traditionally it was thought that antibiotic therapy alone was ineffective, and that prompt nephrectomy was necessary. ${ }^{8}$ 


\section{BMJ Case Reports}

Previous case reports of emphysematous pyelonephritis made four classifications of the condition based on findings from CT imaging. Class 1 was the milder form and class 4 the severe form. ${ }^{2}$ Class 1 and 2 were successfully treated conservatively with antibiotics alone or with percutaneous drainage plus antibiotics. Among class 3 and 4 patients, about $85 \%$ were successfully treated with percutaneous drainage plus antibiotics. The success rate in those treated surgically was $90 \%$.

The clinical presentation of emphysematous pyelonephritis was similar to that of upper urinary tract infection with fever, nausea and vomiting, lethargy, confusion, dyspnoea and shock. Laboratory data showed high glycosylate haemoglobin, leukocytosis, thrombocytopenia and pyuria. ${ }^{2}$ These findings were in agreement with those reported in the literature. Hui and Tokeshi reported a case of emphysematous pyelonephritis treated with nephrectomy, and suggested that based on available data surgical treatment appeared to be the preferred treatment. ${ }^{12}$ Chen et al described 10 years of experience with 25 emphysematous pyelonephritis patients, of which $80 \%$ were treated conservatively with percutaneous drainage plus antibiotics, $12 \%$ underwent nephrectomy and $8 \%$ died. ${ }^{13}$ Shokeir et al reviewed a 15 -year experience with 20 patients with emphysematous pyelonephritis; he emphasised immediate nephrectomy as soon as the patient was medically stable. ${ }^{1}$ Kondo et al, ${ }^{14}$ Punnose et al, ${ }^{15}$ Jain et al ${ }^{16}$ and Best et a ${ }^{17}$ all have described cases of emphysematous pyelonephritis treated successfully with antibiotics alone. Angulo et a ${ }^{18}$ and Tahir et a ${ }^{19}$ reported cases of bilateral emphysematous pyelonephritis that were successfully treated with antibiotics alone.

Currently there is no consensus on the management of emphysematous pyelonephritis. Some have advocated conservative management and others surgical treatment.

\section{Learning points}

- Emphysematous pyelonephritis is a life-threatening condition with bad prognosis.

- Early diagnosis and immediate application of therapeutic measures are imperative for positive outcome.

- Urgent medical intervention in saving patients like the one described.

- It is important to stress that even though imaging is the most reliable diagnostic modality, the initial management of any patient with emphysematous pyelonephritis is resuscitation that include: fluid/ haemodynamic status, glucose control and administration of an empirical antibiotic regimen until the culture sensitivities are available.

- If conservative treatment fails, surgery should be considered without delay.
Randomised controlled trials are required to resolve this issue of whether conservative or surgical management is the best treatment for this rare and fatal condition. This is going to be difficult, as the condition is rare, which determines what cannot be achieved or might not be achieved; therefore, this question might not be answered. Alternatively, retrospective studies are possible, but they would not be able solve this issue, because errors due to confounding variables and bias are more common in retrospective studies than in prospective studies. Until then, both treatment modalities can be used, based on the severity of the condition. Conservative management should be tried first, and if there is no improvement, surgery should immediately be undertaken, as it was in this case.

\section{Competing interests None.}

Patient consent Obtained.

\section{REFERENCES}

1. Shokeir AA, El-Azab M, Mohsen T, et al. Emphysematous pyelonephritis: a 15-year experience with 20 cases. Urology 1997;49:343-6.

2. Huang JJ, Tseng CC. Emphysematous pyelonephritis: clinicoradiological classification, management, prognosis, and pathogenesis. Arch Intern Med 2000;160:797-805.

3. Michaeli J, Mogle P, Perlberg S, et al. Emphysematous pyelonephritis. J Urol 1984;131:203-8.

4. Kelly HA, MacCallum WG. Pneumaturia. JAMA 1898;31:375-81.

5. Ouellet LM, Brook MP. Emphysematous pyelonephritis: an emergency indication for the plain abdominal radiograph. Ann Emerg Med 1988;17:722-4.

6. Evanoff GV, Thompson CS, Foley R, et al. Spectrum of gas within the kidney. Emphysematous pyelonephritis and emphysematous pyelitis. Am J Med 1987;83:149-54.

7. Chen KW, Huang JJ, Wu MH, et al. Gas in hepatic veins: a rare and critical presentation of emphysematous pyelonephritis. J Urol 1994;151:125-6.

8. Cook DJ, Achong MR, Dobranowski J. Emphysematous pyelonephritis. Complicated urinary tract infection in diabetes. Diabetes Care 1989;12:229-32.

9. Andersen JB. Pyelonephritis emphysematosa. En alvorlig komplikation til diabetes mellitus. Ugeskr Laeger 1992;154:1419-21.

10. Wang JM, Lim HK, Pang KK. Emphysematous pyelonephritis. Scand J Urol Nephrol 2007:41:223-9.

11. Joris L, van Daele G, Timmermans U, et al. Emphysematous pyelonephritis. Intensive Care Med 1989;15:206-8.

12. Hui L, Tokeshi J. Emphysematous pyelonephritis. Hawaii Med J 2000:59:336-7.

13. Chen MT, Huang CN, Chou YH, et al. Percutaneous drainage in the treatment of emphysematous pyelonephritis: 10-year experience. J Urol 1997;157:1569-73.

14. Kondo T, Okuda H, Suzuki M, et al. A case of emphysematous pyelonephritis improved with conservative therapy - indication for conservative therapy. Hinyokika Kiyo 2000;46:335-8.

15. Punnose J, Yahya TM, Premchandran JS, et al. Emphysematous pyelonephritis responding to medical therapy. Int J Clin Pract 1997;51:468-70.

16. Jain SK, Agarwal N, Chaturvedi SK. Emphysematous pyelonephritis: a rare presentation. J Postgrad Med 2000;46:31-2.

17. Best CD, Terris MK, Tacker JR, et al. Clinical and radiological findings in patients with gas forming renal abscess treated conservatively. J Urol 1999;162:1273-6.

18. Angulo JC, Dehaini A, Escribano J, et al. Successful conservative management of emphysematous pyelonephritis, bilateral or in a solitary kidney. Scand J Urol Nephrol 1997;31:193-7.

19. Tahir H, Thomas G, Sheerin N, et al. Successful medical treatment of acute bilateral emphysematous pyelonephritis. Am J Kidney Dis 2000;36:1267-70. 


\section{BMJ Case Reports}

This pdf has been created automatically from the final edited text and images.

Copyright 2011 BMJ Publishing Group. All rights reserved. For permission to reuse any of this content visit http://group.bmj.com/group/rights-licensing/permissions.

BMJ Case Report Fellows may re-use this article for personal use and teaching without any further permission.

Please cite this article as follows (you will need to access the article online to obtain the date of publication).

Surur J. Acute bilateral emphysematous pyelonephritis. BMJ Case Reports 2011;10.1136/bcr.10.2010.3425, date of publication

Become a Fellow of BMJ Case Reports today and you can:

- Submit as many cases as you like

- Enjoy fast sympathetic peer review and rapid publication of accepted articles

- Access all the published articles

- Re-use any of the published material for personal use and teaching without further permission

For information on Institutional Fellowships contact consortiasales@bmjgroup.com

Visit casereports.bmj.com for more articles like this and to become a Fellow 